\title{
Normal study or minor motor disorders detected on high-resolution oesophageal manometry - are they relevant?
}

\author{
Mayank Jain \\ Arihant Hospital and Research Centre, Indore, India
}

Key words: manometry, oesophageal, normal, motility disorder.

\begin{abstract}
Address for correspondence: Dr. Mayank Jain, Arihant Hospital and Research Centre, 283-A Gumasta Nagar, Indore -452009, India,
\end{abstract} phone: 917312365688, e-mail: mayank4670@rediffmail.com

\begin{abstract}
Introduction: The clinical significance of normal motility or minor peristaltic disorders, noted on esophageal manometry, in symptomatic patients is unclear.

Aim: To determine the clinical presentation, response to treatment, and outcomes at 2-year follow-up in symptomatic patients with normal manometry and minor peristaltic disorders.

Material and methods: This prospective cohort study included patients between 18 and 80 years old. Patients with previous upper gastrointestinal surgery, prior dilation or myotomy, and major motility disorders or EGJ outflow obstruction as per CC v 3.0 were excluded. The cohort was divided into two groups: normal manometry (Gp1) and minor peristaltic defects (Gp2). Study subjects were contacted for follow-up at 6, 12, and 24 months from the date of initial high-resolution oesophageal manometry study. Details of drug use, symptom control, and requirement of anti-reflux procedures in both groups were obtained.

Results: Fifty-six patients (median age: 42.3 years, males 72\%) formed the study cohort: Gp1 - 35 (62.5\%) and Gp2 - 21 (37.5\%). The patients in the two groups were comparable in terms of symptoms $(p=0.94)$ and treatment $(p=0.15)$ at presentation. On follow-up, the majority of the cases (76.8\%) reported improvement in symptoms at 2 years. None required anti-reflux procedures. There were no significant differences in the symptom profile and drug use in patients in the two groups at various time periods.

Conclusions: Patients with normal and minor oesophageal motor function abnormalities do not worsen over time.
\end{abstract}

\section{Introduction}

High-resolution oesophageal manometry (HREM) is used to diagnose oesophageal motility disorders. However, it has been noted that patient symptoms do not correlate well with changes noted during HREM studies [1]. It is not uncommon to find a normal study or the presence of minor peristaltic defects - ineffective oesophageal motility and fragmented peristalsis - in symptomatic patients. The clinical significance of such findings in symptomatic patients remains unclear.

\footnotetext{
Aim

The present study was undertaken to determine the clinical presentation of patients with normal manometry and minor peristaltic disorders. The patients were
}

followed up at regular intervals for 2 years to determine the response to treatment and outcomes in these cases.

\section{Material and methods}

The present study is a prospective cohort study. Patients between 18 and 80 years of age, who were referred to the author for HREM evaluation between January 2014 and April 2016, were initially enrolled. Oesophageal manometry was performed in a supine position with $10 \times 5 \mathrm{ml}$ water swallows and reported using Chicago Classification (CC) $\vee 3.0$ by a single observer. Those tracings which had been reported using CC 2.0 were reinterpreted using the newer classification.

Exclusion criteria: Unwilling to participate, age $<18$ years, previous upper gastrointestinal surgery, prior dilation or myotomy, oesophageal stricture, techni- 
cally inadequate study, and major motility disorders or EGJ outflow obstruction as per CC $\vee$ 3.0.

Case records were reviewed for clinical history, endoscopic findings, and treatment offered (Figure 1). The patients were classified into two groups: those with normal manometry (Gp1) and those with minor peristaltic defects (Gp2). Study subjects were followed up at 6 months, 12 months, and 24 months from the date of initial HREM study. This was done either by at least two direct consultations (48 cases) or telephonic interview (8 cases). Details of drug use (type and frequency), symptom control (improvement/no change/worsening), and requirement of anti-reflux procedures (endoscopic/ surgical) in both groups were obtained.

Written, informed consent was taken at the time of enrolment from each patient. The study was approved by the local Ethics Committee and was performed in accordance with the ethical standards as laid down in the 1964 Declaration of Helsinki and its later amendments.

\section{Statistical analysis}

Descriptive statistics were used to characterise the patient cohort. Comparison between patient groups was made by using the $\chi^{2}$ test. A $p$-value of $<0.05$ was considered significant.

\section{Results}

Fifty-six patients formed the study cohort. The median age was 42 years (range: $21-78$ years), and males outnumbered the females ( $48,72 \%$ vs. $18,28 \%)$. Normal manometry (Gp1) was noted in 35 (62.5\%) and minor peristaltic disorders (Gp2) in 21 (37.5\%) patients. Upper gastrointestinal endoscopy was normal in 48 cases, while 8 showed low-grade reflux esophagitis (Los Angeles grade $\mathrm{A}$ ).

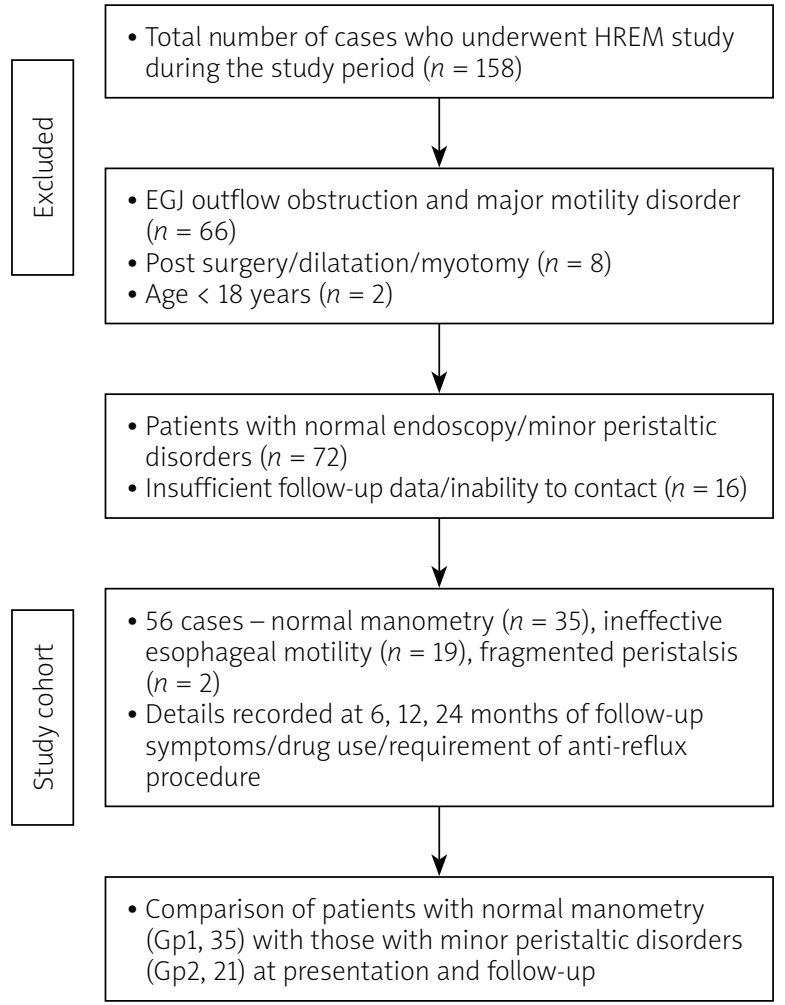

Figure 1. Study methodology

Table I shows the indications for HREM study in the study cohort. The patients in the two groups were comparable in terms of symptoms at presentation. The details of drugs prescribed at the initial presentation in the two groups are shown in Table II. The majority of the cases were prescribed proton pump inhibitors \pm prokinetic agents. Six patients were prescribed additional sodium alginate, and one patient was given pyridostigmine for large breaks in peristalsis.

Table I. Indications of HREM study in the study cohort

\begin{tabular}{|c|c|c|c|}
\hline Symptoms* & Gp1 $(n=35)$ & $\mathrm{Gp} 2(n=21)$ & $P$-value \\
\hline GERD (heartburn/regurgitation/extra-oesophageal symptoms) & $23(65.7 \%)$ & $15(71.4 \%)$ & 0.94 \\
\hline Chest pain & $9(25.7 \%)$ & $4(19 \%)$ & \\
\hline Dysphagia & $5(14.3 \%)$ & $3(14.3 \%)$ & \\
\hline Others (belching/bloating/epigastric pain) & $12(34.3 \%)$ & $8(38.1 \%)$ & \\
\hline
\end{tabular}

*Some patients had combination of symptoms.

Table II. Treatment offered at initial presentation in the study cohort

\begin{tabular}{|c|c|c|c|}
\hline Drugs prescribed & Gp1 $(n=35)$ & $\mathrm{Gp} 2(n=21)$ & $P$-value \\
\hline Proton pump inhibitors alone & $12(34.3 \%)$ & $10(47.6 \%)$ & 0.15 \\
\hline Prokinetics alone & $11(31.4 \%)$ & $1(4.8 \%)$ & \\
\hline Combination of the above two groups & $12(34.3 \%)$ & $9(42.9 \%)$ & \\
\hline $\begin{array}{l}\text { Others (along with the above), e.g. sodium alginate, } \\
\text { pyridostigmine }\end{array}$ & $4(11.4 \%)$ & $3(14.3 \%)$ & \\
\hline
\end{tabular}


Table III. Details of follow-up

\begin{tabular}{|c|c|c|c|}
\hline Parameters & Gp1 $(n=35)$ & $\mathrm{Gp} 2(n=21)$ & $P$-value \\
\hline \multicolumn{4}{|l|}{ 6-month follow-up: } \\
\hline \multicolumn{3}{|l|}{ Symptoms: } & \multirow[t]{4}{*}{0.83} \\
\hline Improved & $21(60 \%)$ & $12(57.1 \%)$ & \\
\hline No change & $14(40 \%)$ & $9(42.9 \%)$ & \\
\hline Worsened & 0.0 & 0.0 & \\
\hline \multicolumn{3}{|l|}{ Medications: } & \multirow[t]{5}{*}{0.29} \\
\hline Continuing every day & $12(34.3 \%)$ & $12(57 \%)$ & \\
\hline On demand & $20(57.1 \%)$ & $8(38.1 \%)$ & \\
\hline Stopped & $3(8.5 \%)$ & $1(4.8 \%)$ & \\
\hline Use of alternative medications & $2(5.7 \%)$ & $3(14.3 \%)$ & \\
\hline Requirement of surgery & Nil & Nil & - \\
\hline \multicolumn{4}{|l|}{ 12-month follow-up: } \\
\hline \multicolumn{3}{|l|}{ Symptoms: } & \multirow[t]{4}{*}{0.54} \\
\hline Improved & $24(68.5 \%)$ & $16(76.2 \%)$ & \\
\hline No change & $11(31.5 \%)$ & $5(23.8 \%)$ & \\
\hline Worsened & 0.0 & 0.0 & \\
\hline \multicolumn{3}{|l|}{ Medications: } & \multirow[t]{5}{*}{0.12} \\
\hline Continuing every day & $10(28.6 \%)$ & $12(57.2 \%)$ & \\
\hline On demand & $21(60 \%)$ & $6(28.6 \%)$ & \\
\hline Stopped & $4(11.4 \%)$ & $3(14.3 \%)$ & \\
\hline Use of alternative medications & $3(8.5 \%)$ & $3(14.3 \%)$ & \\
\hline Requirement of surgery & Nil & Nil & - \\
\hline \multicolumn{4}{|l|}{ 24-month follow-up: } \\
\hline \multicolumn{3}{|l|}{ Symptoms: } & \multirow[t]{4}{*}{0.17} \\
\hline Improved & $25(71.4 \%)$ & $18(85.7 \%)$ & \\
\hline No change & $10(28.6 \%)$ & $3(14.3 \%)$ & \\
\hline Worsened & 0.0 & 0.0 & \\
\hline \multicolumn{3}{|l|}{ Medications: } & \multirow[t]{5}{*}{0.18} \\
\hline Continuing every day & $8(22.9 \%)$ & $9(42.9 \%)$ & \\
\hline On demand & $25(71.4 \%)$ & $9(42.9 \%)$ & \\
\hline Stopped & $2(5.7 \%)$ & $3(14.3 \%)$ & \\
\hline Use of alternative medications & $3(8.5 \%)$ & $3(14.3 \%)$ & \\
\hline Requirement of surgery & $\mathrm{Nil}$ & $\mathrm{Nil}$ & - \\
\hline
\end{tabular}

Table III shows the symptom profile and medication use in the study cohort at 6, 12, and 24 months follow-up. There was improvement in symptoms and a corresponding decrease in the everyday intake of medicines in both groups. None of the patients reported worsening while on treatment, and none required surgery. However, nearly one fourth of cases (13/56, 23.2\%) did not notice any significant change in their symptoms at 2 years. Seventeen (30.3\%) cases were continuing drugs on an everyday basis even at 2 years follow-up. A few patients also reported the use of alternative medications like homeopathy/Ayurveda for symptom relief on follow-up. There were no significant differences in the symptom profile and drug use in patients with normal peristalsis and those with minor peristaltic disorders at various time periods during follow-up. However, a greater number of cases in Gp 2 reported symptomatic improvement at the end 
of 1 year (76.2\% vs. $68.5 \%)$ and 2 years ( $85.4 \%$ vs. $71.4 \%)$.

\section{Discussion}

The present study was done to determine the clinical significance of normal manometry and minor manometric abnormalities in symptomatic patients during HREM studies. It was observed that patients with these disorders had similar clinical presentation and were prescribed similar drug treatment. Over a 2-year follow-up there was symptomatic improvement in three fourths of cases, with no requirement of therapeutic endoscopic or surgical intervention. Moreover, there were no significant differences between the two groups, Gp1 and Gp 2, suggesting that these findings have "benign" outcome. Improvement of symptoms was higher in patients with minor peristaltic disorders at 1-year and 2-year follow-up. This is similar to observations in an earlier study [2].

Various authors have investigated the significance of nonspecific oesophageal motility changes. Achem et al. [3], using conventional manometry, followed up 23 patients of non-specific oesophageal dysmotility and chest pain. The authors noted that follow-up manometric studies were normal in $29 \%$ and manometric changes persisted in $57 \%$ of the patients. In 3 (14\%) patients, the pattern evolved into diffuse oesophageal spasm. The study highlighted that mechanisms other than disturbed oesophageal motility may be responsible for the symptoms in these individuals. Similar findings were noted in a study from Israel, in which the majority of the patients with nonspecific oesophageal dysmotility showed improvement on follow-up, and only $6 \%$ progressed to achalasia [4]. Ravi et al. reported long-term outcomes of patients with normal and minor motility disorders [2]. They noted that these patients rarely required interventions related to oesophageal dysfunction during long-term follow-up. It should be noted that this study was done using CC2.0, and 10 cases of nutcracker oesophagus were included in the study cohort. With refinement in reporting using CC, the major motor disorders are now well characterised, and detection is better compared to conventional manometry.

The findings of the present study and above-mentioned data question the significance and clinical relevance of detecting normal manometry and minor peristaltic disorders in HREM studies in symptomatic patients. It is well documented that these changes may be noted in asymptomatic healthy adults as well [5]. Moreover, management strategies in both groups remain similar. Treatment is usually directed towards management of reflux, and there are no effective treatments to restore impaired oesophageal smooth muscle contractility [6].
When patients with normal manometry and minor peristaltic disorders behave in similar way, do we really need these additional classifications? The answer is inconclusive because a few studies have noted that the presence of large breaks is linked to bolus transit failure and fragmented peristalsis to reflux symptoms [7, 8]. The future CC needs to address and clarify these issues.

Limitations: Small sample size; short, 2-year follow-up; no use of videofluoroscopy or 24-hour pH study; no repeat HREM study during follow-up; small number of patients in subgroups of minor peristaltic disorders, i.e. ineffective oesophageal motility and fragmented peristalsis

\section{Conclusions}

Patients with normal and minor oesophageal motor function abnormalities do not worsen over time, and the majority of them show good response to treatment. Those with minor motor function abnormalities are more likely to be better at 2-year follow-up than those with normal studies.

\section{Conflict of interest}

The author declares no conflict of interest.

\section{References}

1. Jain M, Srinivas M, Bawane P, Venkataraman J. Does Chicago classification address symptom correlation with high-resolution esophageal manometry? Euroasian J Hepatogastroenterol 2017; 7: 122-5.

2. Ravi K, Friesen L, Issaka R, et al. Long-term outcomes of patients with normal or minor motor function abnormalities detected by high-resolution esophageal manometry. Clin Gastroenterol Hepatol 2015; 13: 1416-23.

3. Achem SR, Crittenden J, Kolts B, Burton L. Long-term clinical and manometric follow-up of patients with nonspecific esophageal motor disorders. Am J Gastroenterol 1992; 87: 825-30.

4. Naftali T, Levit T, Pomeranz I, et al. Nonspecific esophageal motility disorders may be an early stage of a specific disorder, particularly achalasia. Dis Esophagus 2008; 22: 611-5.

5. Herregods TV, Roman S, Kahrilas PJ, et al. Normative values in esophageal high-resolution manometry. Neurogastroenterol Motil 2015; 27: 175-87.

6. Scheerens C, Tack J, Rommel N. Buspirone, a new drug for the management of patients with ineffective esophageal motility? United European Gastroenterol J 2015; 3: 261-5.

7. Roman S, Lin Z, Kwiatek MA, et al. Weak peristalsis in esophageal pressure topography: classification and association with dysphagia. Am J Gastroenterol 2011; 106: 349-56.

8. Porter RF, Kumar N, Drapekin JE, et al. Fragmented esophageal smooth muscle contraction segments on high resolution manometry: a marker of esophageal hypomotility. Neurogastroenterol Motil 2012; 24: 763-8.

Received: 4.05.2019

Accepted: 8.06.2019 